\title{
Energy intake, energy required and mortality in an older population
}

\author{
Paul H Lee* and Choi-Wan Chan \\ PQ433, School of Nursing, Hong Kong Polytechnic University, Hung Hom, Kowloon, Hong Kong Special \\ Administrative Region, People's Republic of China
}

Submitted 16 November 2015: Final revision received 13 May 2016: Accepted 2 June 2016: First published online 13 July 2016

\begin{abstract}
Objectives: The present study evaluated the association between energy intake, energy required and mortality in older adults.

Design: A cohort study with a mean of 10.67 (SD 4.74) years of follow-up. Participants completed a $24 \mathrm{~h}$ dietary recall. Energy required per day was computed by BMR. Deaths through 2006 were identified from the National Death Index. A Cox regression was used to estimate the hazard ratios (HR) of quantiles of energy intake and energy required on all-cause and CVD mortality, adjusting for demographics, socio-economic status and co-morbidity.

Setting: The National Health and Nutrition Examination Survey (NHANES) III, 1988-1994.

Subjects: A total of 4846 participants aged 60 years or above were analysed.

Results: Within the follow-up period, there were a total of 2954 deaths (61.0\%),

$51.9 \%$ were caused by CVD. Relative to those in quartile 1 of energy intake, only quartile 4 was associated with all-cause mortality and CVD mortality with HR of 0.86 (95\% CI $0.77,0.96, P=0.006$ ) and 0.76 (95\% CI $0.65,0.89, P=0.001$ ), respectively. On the other hand, relative to those in quartile 1 of energy required, all quartiles of participants had a lower risk of all-cause mortality and CVD mortality. The interaction effects between energy intake and energy required with all-cause and CVD mortality were insignificant $(P=0.70$ and $0 \cdot 61$, respectively). Conclusions: Independent of energy required, higher energy intake was associated with lower HR of both all-cause and CVD mortality in older adults.
\end{abstract}

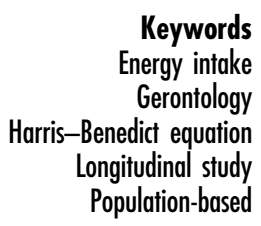

The effect of energy intake on mortality and morbidity has been the scope of intensive research for many years ${ }^{(1-3)}$, particularly among critically ill hospital populations that undertake minimal physical activity ${ }^{(3-8)}$. The association between energy intake and the clinical outcomes of critically ill patients on nutritional therapy from observational studies suggested that those with higher energy intake had higher chances of survival and hospital discharge ${ }^{(4,5)}$. A narrative review also noted that improving the adequacy of enteral nutrition by moving intake to $>25 \%$ but $<66 \%$ of the set energy intake target might be associated with clinical benefits ${ }^{(6)}$; the authors acknowledged, however, that the observational studies could be limited by unmeasurable factors and residual confounding. Similarly, other research among critical ill patients showed that increasing energy intake was associated with lower allcause mortality ${ }^{(7,8)}$. Most studies appeared to conclude that critically ill patients were undernourished and that increasing energy intake was beneficial to them.

Similar findings were also found in population-based, community-dwelling samples. Several large-scale epidemiological studies revealed that higher energy intake appeared beneficial to mortality. For example, in a population-based cohort of non-smoking JapaneseAmerican males with a 36-year follow up, those with less than half of the mean energy intake had elevated ageadjusted all-cause and cardiovascular mortality rates ${ }^{(2)}$. A population-based meta-analysis in Cuba showed that increased energy intake during the period of 1990-2005 was associated with reductions in CVD and diabetes mortality ${ }^{(9)}$. Another population-based prospective study also found that individuals with low energy intake did not have lower mortality than those with average or high energy intake, and the authors suggested that the equilibrium between energy required and energy intake and the study characteristics should be considered in the evaluation $^{(10)}$. These findings contrast with the hypothesized pathway that higher energy intake leads to an increase of BMI and related morbidity and hence mortality $^{(11)}$.

We believe that energy required will modify the effect between energy intake and mortality. We acknowledge that energy required/consumption varies across different persons and is dependent on age, sex, body composition/ 
nutritional status and physical activity level ${ }^{(12)}$. Among the general population, the associations between physical activity and mortality ${ }^{(13)}$, and between daily energy intake, physical activity and CVD and diabetes mortality, have been well established ${ }^{(9)}$. However, little research has been conducted on the optimal level of energy intake in improving health outcomes among the communitydwelling elderly, and results obtained in the general population cannot be directly applied to the elderly since they have very different metabolism rates and gastrointestinal function compared with their adult counterparts ${ }^{(14)}$. This is central to the present study evaluating the interaction effects of energy intake and energy required with all-cause and CVD mortality among participants aged 60 years or above in a large, representative US cohort. Our study takes account of factors such as age, sex, body composition (BMI) and physical activity level while calculating energy consumption.

\section{Methods}

\section{Participants}

The current study utilized data collected from participants in the National Health and Nutrition Examination Survey (NHANES) III conducted from October 1988 to October 1994. The NHANES III, conducted by the National Center for Health Statistics, Centers for Disease Control and Prevention, was designed to assess the health and nutritional status of US residents (http://www.cdc.gov/nchs/nhanes/ about_nhanes.htm). The sample was representative of the US population and was selected using a multistage probability cluster design. Participants were invited to complete a survey and a health examination; details can be obtained from the NHANES website (http://www.cdc. gov/nchs/nhanes/nhanes_questionnaires.htm). A total of 33994 participants completed the survey; those aged 59 years or below and those with less than 1 year of follow-up were excluded from the present study, leaving a final sample of 4846 .

The NHANES III data were linked with death certificate data in the National Death Index through 31 December 2006. Participants had been followed for 10.67 (SD 4.74) years on average. The cause of death was coded using the International Classification of Diseases, 9th revision (ICD-9) until 1998 (when it was re-coded using the 10th revision, ICD-10) and the ICD-10 was used from 1999. Mortality caused by CVD was defined as ICD-10 codes I00-I78. Participants with no mortality status were assumed to be alive.

\section{Dietary recall}

At baseline, participants were interviewed by trained dietary interviewers to complete a $24 \mathrm{~h}$ dietary recall and their energy intake was computed based on the University of Minnesota Nutrition Coordinating Center nutrient database data ${ }^{(15,16)}$. Nutrient supplements and medications were excluded.

Physical activity was assessed using questionnaires including the number of times of walking a mile without stopping, jogging or running, riding a bicycle, swimming, doing aerobics, dancing, doing calisthenics, doing yard work and lifting weights in the past month. Frequency of physical activity per week was computed by summing up the above times and dividing by $4 \cdot 3(\sim 30 / 7)$. Energy required per day was computed as BMR times physical activity factor using the revised Harris-Benedict equation $^{(17)}$ as follows. First, BMR was computed using the following equations.

For men:

$$
\begin{aligned}
13.397 \times \text { weight }(\mathrm{kg}) & +4.799 \times \text { height }(\mathrm{m}) \\
& -5.677 \times \text { age }(\text { years })+88.362
\end{aligned}
$$

For women:

$$
\begin{aligned}
9.247 \times \text { weight }(\mathrm{kg}) & +3.098 \times \text { height }(\mathrm{m}) \\
& -4.330 \times \text { age }(\text { years })+447.593 .
\end{aligned}
$$

The energy required per day was then computed as BMR times $1.2,1.375,1.55,1.725$ or 1.9 if the physical activity frequency was $<1,1-3,4-5,6-7$ or $>7$ times per week. Both energy intake and energy required were grouped into quartiles. As the energy required was associated with age, gender, weight and height, these variables were not adjusted for in the subsequent analysis to avoid double adjustment.

\section{Other measurements}

At the mobile examination centre, blood pressure was measured by physicians. Blood pressure was measured three times and the mean values were used. Participants were classified as having hypertension if they reported having doctor-diagnosed hypertension or had a blood pressure of $\geq 140 / 90 \mathrm{mmHg}$. A blood test was conducted at the mobile examination centre to obtain the plasma glucose level and C-reactive protein level. Participants were classified as having type 2 diabetes if they either reported having doctor-diagnosed type 2 diabetes or had fasting plasma glucose $>126 \mathrm{mg} / \mathrm{dl}$ or glycated $\mathrm{Hb}>6.5 \%$. Participants were classified as having high C-reactive protein level if $>3.0 \mathrm{mg} / \mathrm{l}$. Height and weight were measured by trained interviewers and BMI was calculated as [weight $(\mathrm{kg})] /[\text { height }(\mathrm{m})]^{2}$.

\section{Statistical analysis}

All confounders with missing data were imputed using the additive regression available in the package Hmisc of $\mathrm{R}$. The association between energy intake and energy required was computed using Spearman correlation. Cox regression was used to estimate the hazard ratios (HR) of energy intake and energy required on all-cause and CVD 
mortality, with the first quartile as the reference group. HR were adjusted for race, education level, smoking status, hypertension, type 2 diabetes and high C-reactive protein level, with age, sex and BMI unadjusted to avoid double adjustment. Three sensitivity analyses were conducted: (i) by comparing the HR with and without adjustment for age, sex and BMI; (ii) by comparing the HR of energy intake with adjustment for energy required or adjustment for BMR plus physical activity level (as quartiles); and (iii) by comparing the HR with and without omission of deaths within 1-3 years of recruitment. The results can be found in the online supplementary material, Tables S1 to S6. Linear associations of energy intake and energy required with mortality were also examined, with Cox regression on their original level. The interaction of energy intake and energy required was examined in separate Cox regressions. All statistical analyses were done using the statistical software package IBM SPSS Statistics Version 20.0.

\section{Results}

Table 1 shows the characteristics of the 4846 participants aged 60 years or above by energy intake. The mean age of the sample was 72.26 (SD 8.02 ) years. The mean energy intake and energy required of the participants were 6972.34 (sD 3147.46$) \mathrm{kJ} / \mathrm{d}(1666.43(\mathrm{sD} 752 \cdot 26) \mathrm{kcal} / \mathrm{d})$ and 8378.29 (SD 2116.43$) \mathrm{kJ} / \mathrm{d}(2002.46$ (SD 505.84$) \mathrm{kcal} / \mathrm{d}$ ), respectively, and they were mildly correlated $(\rho=0.27, P<0.001)$. The first, second, third and fourth quartiles of energy required per day were $<6713.02 \mathrm{~kJ} \quad(<1604.45 \mathrm{kcal}), \quad 6713.02-$ $8101 \cdot 14 \mathrm{~kJ} \quad(1604 \cdot 45-1936 \cdot 22 \mathrm{kcal}), \quad 8101 \cdot 14-9739 \cdot 72 \mathrm{~kJ}$ $(1936.22-2327.85 \mathrm{kcal})$ and $\geq 9739.72 \mathrm{~kJ}(\geq 2327.85 \mathrm{kcal})$, respectively. Mean BMI was $27 \cdot 06$ (SD 5.13) kg/m². Across different quartiles of energy intake, there were significant differences in physical activity frequency per week and energy required per day. Younger participants, males, nonHispanic whites, those with at least 12 years of education, smokers, those without hypertension, without diabetes, with lower BMI, with higher physical activity frequency per week and with more energy required per day were more likely to be in the higher energy intake quartiles.

Within the follow-up period, there were a total of 2954 deaths $(61.0 \%)$, more than half ( $n$ 1532) of which were caused by CVD. Table 2 shows the characteristics of the 4846 participants by mortality status. Lower energy intake per day, lower physical activity frequency per week, lower energy required per day, older age, being male, non-Hispanic white, fewer than 12 years of education, hypertension, type 2 diabetes and lower BMI were associated with both all-cause and CVD mortality, while being a non-smoker and having a high C-reactive protein level were associated with all-cause mortality only.

Figure 1(a) shows the HR of energy intake and energy required on all-cause mortality. Relative to those in quartile 1 of energy intake, only quartile 4 was associated with all-cause mortality with HR of 0.86 (95\% CI 0.77, 0.96, $P=0.006)$. The linear association of energy intake with all-cause mortality was also significant $(P<0 \cdot 001)$. On the other hand, relative to those in quartile 1 of energy required, all quartiles of participants had a lower risk of all-cause mortality, with HR ranging from 0.63 (quartile 4) to 0.72 (quartile 2 ). Similarly to energy intake, the linear association of energy required with all-cause mortality was also significant $(P<0 \cdot 001)$. Sensitivity analysis showed that adjusting for age, sex and BMI had no effect on the HR (see online supplementary material, Table S1). Similarly, changing the adjustment of energy required to BMR plus physical activity level, or changing the inclusion criterion from $>1$ year of follow-up period to $>3$ years, had no effect on the HR (Tables S3-S6).

Figure 1(b) shows the HR of energy intake and energy required on CVD mortality. Relative to those in quartile 1 of energy intake, only quartile 4 was associated with CVD mortality with HR of 0.76 (95\% CI $0.65,0.89, P=0.001)$. The linear association of energy intake with CVD mortality was also significant $(P<0 \cdot 001)$. On the other hand, relative to those in quartile 1 of energy required, all quartiles of participants had a lower risk of CVD mortality, with HR ranging from 0.58 (quartile 4) to 0.68 (quartile 2). Similarly to energy intake, the linear association of energy required with CVD mortality was also significant $(P<0.001)$. Sensitivity analysis showed that adjusting for age, sex and BMI had no effect on the HR (see online supplementary material, Table S2).

The interaction effects on all-cause and CVD between energy intake and energy required are demonstrated in Fig. 2(a) and (b), respectively. Energy intake and energy required were independently associated with all-cause and CVD mortality with an insignificant interaction effect $(P=0.70$ and $0 \cdot 61$, respectively). In other words, regardless of the level of energy required, higher energy intake was associated with lower HR of both all-cause and CVD mortality.

\section{Discussion}

Our findings were consistent with those of previous population-wide studies among older population groups, namely that higher energy intake is associated with reduced mortality ${ }^{(2,9,10)}$. For critically ill patients, it has been found that an energy intake of $33-65 \%$ of the energy required is associated with better health outcomes and higher mortality was found in patients who deviated from this level of energy intake. This shows that the adverse effects of food intake (e.g. pulmonary aspiration and hyperglycaemia) override the benefits of nutritional support among the critically ill $^{(4)}$. However, these adverse effects are less applicable to healthy individuals and the results of the current study suggest that the benefits of nutritional support override its disadvantages in this population. Our study also showed that energy intake was 
Table 1 Descriptive statistics of the study participants by quartiles of energy intakeł: adults ( $n$ 4846) aged 60 years or above, National Health and Nutrition Examination Survey (NHANES) III, 1988-1994

\begin{tabular}{|c|c|c|c|c|c|c|c|c|c|c|}
\hline & \multicolumn{2}{|c|}{ Quartile 1 ( $n$ 1211) } & \multicolumn{2}{|c|}{ Quartile 2 (n 1212) } & \multicolumn{2}{|c|}{ Quartile 3 (n 1212) } & \multicolumn{2}{|c|}{ Quartile 4 (n 1211) } & \multicolumn{2}{|c|}{ Total (n 4846) } \\
\hline & Mean or $n$ & SD or $\%$ & Mean or $n$ & SD or $\%$ & Mean or $n$ & SD or $\%$ & Mean or $n$ & SD or $\%$ & Mean or $n$ & SD or $\%$ \\
\hline 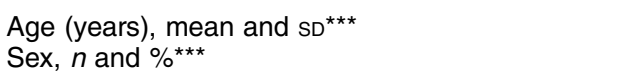 & 73.09 & 8.06 & $72 \cdot 71$ & 8.07 & $72 \cdot 32$ & 7.64 & $70 \cdot 89$ & 7.85 & $72 \cdot 26$ & 8.02 \\
\hline $\begin{array}{l}\text { Male } \\
\text { Race, } n \text { and \%***}\end{array}$ & 346 & $28 \cdot 60$ & 480 & $39 \cdot 67$ & 619 & $50 \cdot 95$ & 884 & 73.00 & 2329 & 48.06 \\
\hline $\begin{array}{l}\text { Race, } n \text { and \%*** } \\
\text { Non-Hispanic White } \\
\text { Non-Hispanic Black } \\
\text { Mexican-American } \\
\text { Others }\end{array}$ & $\begin{array}{r}593 \\
313 \\
271 \\
33\end{array}$ & $\begin{array}{r}49 \cdot 01 \\
25 \cdot 87 \\
22 \cdot 40 \\
2 \cdot 73\end{array}$ & $\begin{array}{r}692 \\
249 \\
238 \\
31\end{array}$ & $\begin{array}{r}57 \cdot 19 \\
20 \cdot 58 \\
19 \cdot 67 \\
2.56\end{array}$ & $\begin{array}{r}760 \\
204 \\
211 \\
40\end{array}$ & $\begin{array}{r}62 \cdot 55 \\
16 \cdot 79 \\
17 \cdot 37 \\
3 \cdot 29\end{array}$ & $\begin{array}{r}765 \\
203 \\
206 \\
37\end{array}$ & $\begin{array}{r}63 \cdot 17 \\
16 \cdot 76 \\
17 \cdot 01 \\
3 \cdot 06\end{array}$ & $\begin{array}{r}2810 \\
969 \\
926 \\
141\end{array}$ & $\begin{array}{r}57.99 \\
20 \cdot 00 \\
19.11 \\
2.91\end{array}$ \\
\hline $\begin{array}{l}\text { Education, } n \text { and \%*** } \\
\quad \geq 12 \text { years } \\
\text { Smoker, } n \text { and \%** }\end{array}$ & 388 & $32 \cdot 07$ & 521 & 43.06 & 600 & $49 \cdot 38$ & 635 & $52 \cdot 44$ & 2144 & $44 \cdot 24$ \\
\hline $\begin{array}{l}\text { Yes } \\
\text { Hypertension§, } n \text { and \%*** }\end{array}$ & 215 & $17 \cdot 77$ & 193 & $15 \cdot 95$ & 201 & $16 \cdot 54$ & 260 & $21 \cdot 47$ & 869 & 17.93 \\
\hline $\begin{array}{l}\text { Yes } \\
\text { Type } 2 \text { diabetesll, } n \text { and }\end{array}$ & 885 & $73 \cdot 14$ & 818 & $67 \cdot 60$ & 781 & $64 \cdot 28$ & 734 & $60 \cdot 61$ & 3218 & $66 \cdot 41$ \\
\hline $\begin{array}{l}\text { Yes } \\
\text { High C-reactive protein level} \mid \boldsymbol{l}, n \text { and } \%\end{array}$ & 297 & 24.55 & 235 & $19 \cdot 42$ & 201 & $16 \cdot 54$ & 152 & $12 \cdot 55$ & 885 & $18 \cdot 26$ \\
\hline $\begin{array}{l}\text { Yes } \\
\text { BMI }\left(\mathrm{kg} / \mathrm{m}^{2}\right) \text {, mean and } \mathrm{SD}^{\star *}\end{array}$ & $\begin{array}{l}36 \\
27 \cdot 44\end{array}$ & $\begin{array}{l}2.98 \\
5.40\end{array}$ & $\begin{array}{l}23 \\
27 \cdot 15\end{array}$ & $\begin{array}{l}1.90 \\
5.33\end{array}$ & $\begin{array}{l}28 \\
26 \cdot 89\end{array}$ & $\begin{array}{l}2 \cdot 30 \\
4 \cdot 95\end{array}$ & $\begin{array}{l}20 \\
26 \cdot 76\end{array}$ & $\begin{array}{l}1.65 \\
4.78\end{array}$ & $\begin{array}{l}107 \\
27.06\end{array}$ & $\begin{array}{l}2 \cdot 21 \\
5 \cdot 13\end{array}$ \\
\hline $\begin{array}{l}\text { Physical activity times per week, mean and } \mathrm{SD}^{\star \star *} \\
\text { Energy required }(\mathrm{kJ} / \mathrm{d}) \text { mean and } \mathrm{SD}^{\star \star \star}\end{array}$ & $\begin{array}{r}2.67 \\
7735.38\end{array}$ & $\begin{array}{r}3.66 \\
1967.15\end{array}$ & $\begin{array}{r}3.12 \\
8127.50\end{array}$ & $\begin{array}{r}3.85 \\
2017.48\end{array}$ & $\begin{array}{r}3.24 \\
8460.93\end{array}$ & $\begin{array}{r}3.80 \\
2063.05\end{array}$ & $\begin{array}{r}3.54 \\
9188.32\end{array}$ & $\begin{array}{r}3.66 \\
2142.96\end{array}$ & $\begin{array}{r}3.14 \\
8378.29\end{array}$ & $\begin{array}{r}3.76 \\
2116.43\end{array}$ \\
\hline $\begin{array}{l}\text { Energy required (kcal/d), mean and } \mathrm{SD}^{\star \star *} \\
\text { Mortality (all-cause), } n \text { and \%*** }\end{array}$ & 1848.80 & 470.16 & 1942.52 & $482 \cdot 19$ & $2022 \cdot 21$ & 493.08 & 2196.06 & $512 \cdot 18$ & $2002 \cdot 46$ & 505.84 \\
\hline $\begin{array}{l}\text { Yes } \\
\text { Mortality (CVD), } n \text { and \%*** }\end{array}$ & 796 & $65 \cdot 79$ & 754 & $62 \cdot 31$ & 743 & $61 \cdot 15$ & 661 & 54.58 & 2954 & 60.96 \\
\hline Yes & 427 & $35 \cdot 29$ & 410 & 33.88 & 392 & $32 \cdot 26$ & 303 & $25 \cdot 02$ & 1532 & $31 \cdot 61$ \\
\hline
\end{tabular}

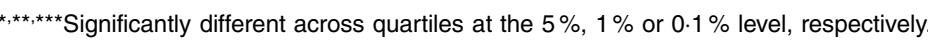

Energy intake: quartile 1, <4786.50 kJ/d (<1144.00 kcal/d); quartile 2, 4786.50-6464.28 kJ/d (1144.00-1545.00 kcal/d); quartile 3, 6464.28-8536.41 kJ/d (1545.00-2040.25 kcal/d); quartile 4, $\geq 8536.41 \mathrm{~kJ} / \mathrm{d}$ ( $\geq 2040.25 \mathrm{kcal} / \mathrm{d})$. In Total sample, mean (sD) energy intake: $6972.34(3147.46) \mathrm{kJ} / \mathrm{d}(1666.43(752.26) \mathrm{kcal} / \mathrm{d})$.

§Evidence of hypertension: blood pressure $\geq 140 / 90 \mathrm{mmHg}$ or self-reported doctor-diagnosed hypertension

IEvidence of type 2 diabetes: fasting plasma glucose $>126 \mathrm{mg} / \mathrm{dll}$, glycated $\mathrm{Hb}>6.5 \%$ or self-reported doctor-diagnosed type 2 diabetes.

C-reactive protein $>3.0 \mathrm{mg} / \mathrm{l}$. 
Table 2 Descriptive statistics of the study participants by mortality status within a mean follow-up period of 10.67 (SD 4.74) years: adults ( $n$ 4846) aged 60 years or above, National Health and Nutrition Examination Survey (NHANES) III, 1988-1994

\begin{tabular}{|c|c|c|c|c|c|c|c|c|}
\hline & \multicolumn{2}{|c|}{ Alive ( $n$ 1892) } & \multicolumn{2}{|c|}{ Dead (all-cause) ( $n$ 2954) } & \multicolumn{2}{|c|}{ Dead (CVD) ( $n$ 1532) } & \multicolumn{2}{|c|}{ Total ( $n$ 4846) } \\
\hline & Mean & SD & Mean & SD & Mean & SD & Mean & SD \\
\hline Energy intake $(\mathrm{kJ} / \mathrm{d})^{\star \star \star}$, ,†† & 7268.65 & $3249 \cdot 71$ & 6782.56 & $3065 \cdot 74$ & 6611.31 & 2969.47 & $6972 \cdot 34$ & 3147.46 \\
\hline Energy intake $(\mathrm{kcal} / \mathrm{d})^{* \star \star \star}, \dagger \dagger \dagger$ & 1737.25 & 776.70 & 1621.07 & 732.73 & $1580 \cdot 14$ & 709.72 & 1666.43 & 752.26 \\
\hline Physical activity frequency per week ${ }^{* * *}, \dagger \dagger \dagger$ & 3.42 & 3.78 & 2.97 & 3.73 & 2.96 & 3.78 & 3.14 & 3.76 \\
\hline Energy required $(\mathrm{kJ} / \mathrm{d})^{\star \star *}, \mathrm{\dagger}+\dagger$ & $8700 \cdot 59$ & $2073 \cdot 21$ & 8171.85 & $2118 \cdot 40$ & 8085.96 & $2067 \cdot 31$ & 8378.29 & 2116.43 \\
\hline Energy required $(\mathrm{kcal} / \mathrm{d})^{\star \star \star},+\dagger \dagger$ & 2079.49 & 495.51 & $1953 \cdot 12$ & $506 \cdot 31$ & 1932.59 & $494 \cdot 10$ & $2002 \cdot 46$ & 505.84 \\
\hline Age (years) ${ }^{* \star}, \dagger \dagger$ & 67.67 & 5.71 & 75.19 & 7.91 & 75.96 & 7.93 & $72 \cdot 26$ & 8.02 \\
\hline \multirow[t]{2}{*}{ BMI $\left(\mathrm{kg} / \mathrm{m}^{2}\right)^{\star \star \star \star}$, ,†† } & $27 \cdot 71$ & $5 \cdot 04$ & $26 \cdot 65$ & $5 \cdot 14$ & $26 \cdot 73$ & $5 \cdot 24$ & $27 \cdot 06$ & $5 \cdot 13$ \\
\hline & $n$ & $\%$ & $n$ & $\%$ & $n$ & $\%$ & $n$ & $\%$ \\
\hline \multicolumn{9}{|l|}{ Sex ${ }^{\star \star \star}, \dagger \dagger \dagger$} \\
\hline Male & 787 & 41.60 & 1542 & $52 \cdot 20$ & 763 & 49.80 & 2329 & 48.06 \\
\hline \multicolumn{9}{|l|}{ Race $^{\star \star \star}$, ,†† } \\
\hline Non-Hispanic White & 998 & 52.75 & 1812 & $61 \cdot 34$ & 943 & 61.55 & 2810 & 57.99 \\
\hline Non-Hispanic Black & 377 & 19.93 & 592 & 20.04 & 313 & 20.43 & 969 & $20 \cdot 00$ \\
\hline Mexican-American & 439 & $23 \cdot 20$ & 487 & 16.49 & 245 & 15.99 & 926 & $19 \cdot 11$ \\
\hline Others & 78 & $4 \cdot 12$ & 63 & 2.13 & 31 & 2.02 & 141 & 2.91 \\
\hline \multicolumn{9}{|l|}{ Education ${ }^{\star \star \star}, \dagger^{\prime} \dagger$} \\
\hline$\geq 12$ years & 947 & $50 \cdot 05$ & 1197 & $40 \cdot 52$ & 624 & $40 \cdot 73$ & 2144 & $44 \cdot 24$ \\
\hline \multicolumn{9}{|l|}{ Smoker ${ }^{\star \star \star}$} \\
\hline $\begin{array}{l}\text { Yes } \\
\text { Hypertensiont }{ }^{* * *}+t+t\end{array}$ & 277 & $14 \cdot 64$ & 592 & $20 \cdot 04$ & 261 & $17 \cdot 04$ & 869 & $17 \cdot 93$ \\
\hline \multicolumn{9}{|l|}{ Hypertension¥, ${ }^{* \star *}, \dagger \dagger \dagger$} \\
\hline \multicolumn{9}{|l|}{ Type 2 diabetes§, ${ }^{* * \star}, \dagger \dagger \dagger$} \\
\hline \multirow{2}{*}{$\begin{array}{l}\text { Yes } \\
\text { High C-reactive protein levelll, } \\
\text { Yes }\end{array}$} & 231 & $12 \cdot 21$ & 654 & $22 \cdot 14$ & 361 & 23.56 & 885 & $18 \cdot 26$ \\
\hline & 29 & 1.53 & 78 & 2.64 & 37 & 2.42 & 107 & 2.21 \\
\hline
\end{tabular}

${ }_{\star, \star \star, \star \star \star}$ Significantly different between alive and dead (all-cause) at the $5 \%, 1 \%$ or $0.1 \%$ level, respectively.

t,tt,t†tSignificantly different between alive and dead (CVD) at the $5 \%, 1 \%$ or $0.1 \%$ level, respectively.

†Evidence of hypertension: blood pressure $\geq 140 / 90 \mathrm{mmHg}$ or self-reported doctor-diagnosed hypertension.

§Evidence of type 2 diabetes: fasting plasma glucose $>126 \mathrm{mg} / \mathrm{dl}$, glycated $\mathrm{Hb}>6.5 \%$, or self-reported doctor-diagnosed type 2 diabetes.

IIC-reactive protein $>3.0 \mathrm{mg} / \mathrm{l}$.
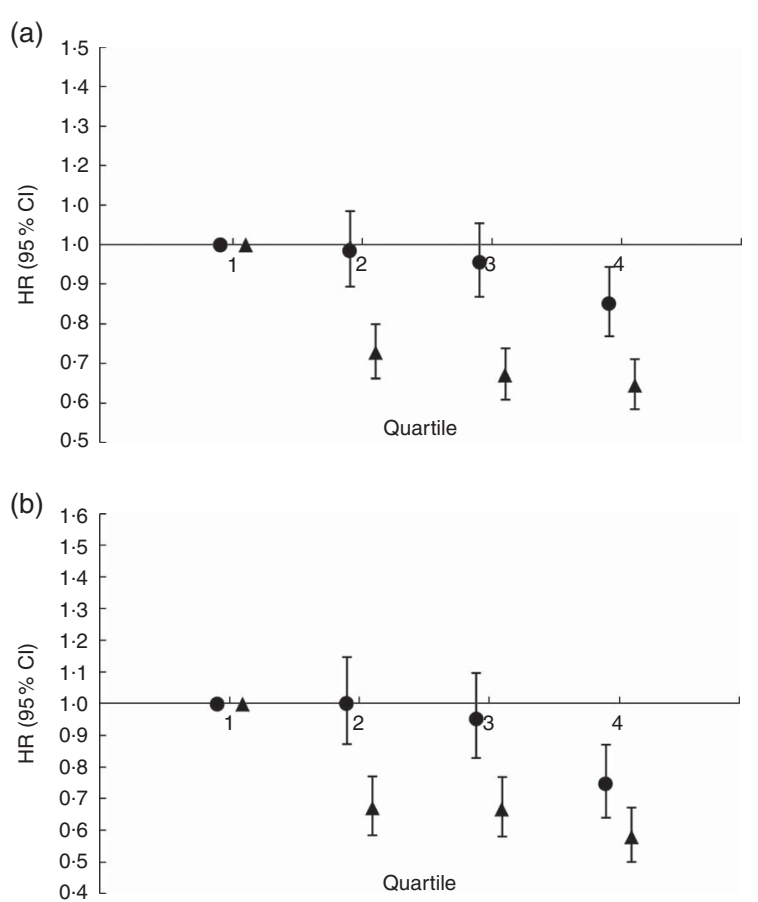

Fig. 1 Hazard ratios (HR), with $95 \%$ confidence intervals represented by vertical bars, of quantiles of energy intake (O) and energy required $(\boldsymbol{\Delta})$ on (a) all-cause mortality and (b) CVD mortality within a mean follow-up period of 10.67 (SD 4.74) years among adults ( $n$ 4846) aged 60 years or above, National Health and Nutrition Examination Survey (NHANES) III, 1988-1994 negatively associated with both all-cause and CVD mortality, regardless of the level of energy requirement; our study did not support our hypothesis that energy requirement modifies the association between energy intake and mortality. The study results did not support the argument that lower energy intake may be beneficial to health ${ }^{(18)}$.

Our findings showed that the people still alive at followup had higher BMI compared with those who died in both bivariate analysis (Table 2) and after adjusting for demographics, socio-economic status and health conditions (results not shown). Although the negative effects of overweight and obesity on mortality have been documented among the young and working-age population ${ }^{(19)}$, BMI is inconsistently correlated with mortality risk among the older population ${ }^{(20-24)}$. A previous study found that overweight and obesity have protective effects in the healthy older population ${ }^{(25)}$ and we postulate that this is a result of excessive body fat serving as a nutritional reserve in times of stress and illness ${ }^{(26,27)}$. In addition, others have shown that increased BMI is positively associated with survival after illness ${ }^{(28,29)}$. In our sample at baseline, nearly two-thirds had hypertension, which might explain our finding that BMI was negatively associated with mortality. This result also suggests a causal pathway of higher energy intake leading to reduced mortality through increased BMI.

Increased energy intake was observed in the fourth quartile $(\sim 9625 \mathrm{~kJ} / \mathrm{d}(\sim 2300 \mathrm{kcal} / \mathrm{d}))$ as a protective factor 
(a)

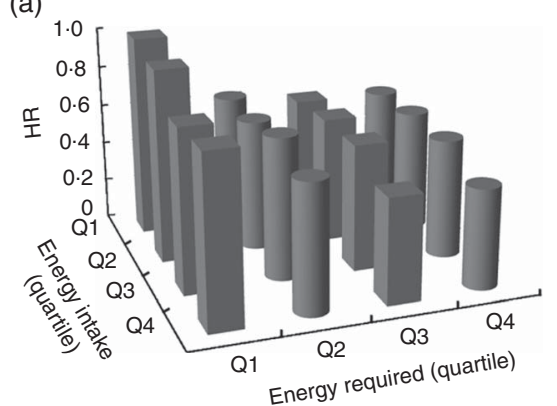

(b)

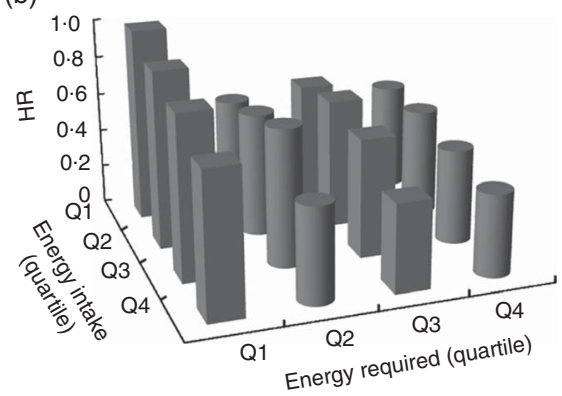

Fig. 2 Hazard ratio (HR) of interaction between quartiles $(\mathrm{Q})$ of energy intake and energy required on (a) all-cause mortality and (b) CVD mortality within a mean follow-up period of 10.67 (SD 4.74) years among adults ( $n$ 4846) aged 60 years or above, National Health and Nutrition Examination Survey (NHANES) III, 1988-1994

to reduce all-cause and CVD mortality after adjusting for confounding; this was further evident in the null interaction of energy intake and energy required with mortality, in which energy intake higher than $\sim 9625 \mathrm{~kJ} / \mathrm{d}$ $(\sim 2300 \mathrm{kcal} / \mathrm{d})$ was protective regardless of the amount of energy required. Likewise, the increased energy required aligned with the increased energy intake to reduce mortality in the analysis shown Fig. 1, in which those requiring more than $6694 \mathrm{~kJ} / \mathrm{d}(1600 \mathrm{kcal} / \mathrm{d})$ have a lower risk of allcause and CVD mortality. To examine the association between intake of energy and mortality, in the current study we included energy required data into the evaluation in order to provide more concrete details of the association. By means of the revised Harris-Benedict equation, the energy required was calculated based on an older adult's physical activity level and BMR in terms of age, weight and height (body size), which paralleled the viewpoint that the equilibrium between energy intake and energy required is influenced by a variety of factors such as age, body size and physical activity ${ }^{(10)}$. Illustration of this energy equilibrium, reflecting health status such as being undernourished to overnourished, underfed to overfed or underweight to overweight, would be a promising parameter for representing the extent to which energy balance affects mortality, which in turn might provide clues to interpreting various previous findings among studies using critically ill hospital inpatient and community populationbased samples.

One of the strengths of the present study is that we made use of data from a large cohort selected by a multistage probability cluster design representing an older US population of diverse nature in terms of sex, race, geography and socio-economic status, consisting of nearly 5000 older participants with a follow-up period of more than 10 years, adjusted for co-morbidity, and the results have high generalizability. Examining the effect of energy intake, energy required and mortality among communitydwelling elderly who were not critically ill might lead to greater homogeneity across possible uncontrolled confounders, such as unreported medical process and disease complications, thus enhancing internal validity.
The study has several limitations. The analysis relied on collection of nutrition and health measurement data at a single time point; we were not able to measure the changes in energy intake and energy required over time. Regarding the validity of the $24 \mathrm{~h}$ dietary recall, slight under-reporting was found in the same data set ${ }^{(30)}$. The self-reported physical activity may be over-reported, as found in other physical activity questionnaires ${ }^{(31)}$. However, under-reporting of dietary and over-reporting of physical activity would not affect the direction of the energy intake-mortality association; hence we believe this limitation is a minor one. In addition, the $24 \mathrm{~h}$ dietary recall may not represent the average energy intake of individual participants. It is possible that the effect of energy intake on mortality was mediated by major life events such as surgery and death of a spouse, but these data were not measured in this study and therefore such hypotheses could not be examined. Finally, concerning the generalizability of the results, the sample consisted of too few underweight participants (only $2 \cdot 13 \%$ had BMI $<18.5 \mathrm{~kg} / \mathrm{m}^{2}$ ).

\section{Acknowledgements}

Financial support: This research received no specific grant from any funding agency in the public, commercial or not-for-profit sectors. Conflict of interest: None. Authorship: Study design and implementation, P.H.L. and C.-W.C.; data analysis, P.H.L.; manuscript writing, interpretation of data and manuscript preparation, P.H.L. and C.-W.C. Ethics of buman subject participation: This study was conducted according to the guidelines laid down in the Declaration of Helsinki and all procedures involving human subjects/ patients were approved by the Centers for Disease Control and Prevention ethics review board. Written informed consent was obtained from all subjects/patients.

\section{Supplementary material}

To view supplementary material for this article, please visit http://dx.doi.org/10.1017/S1368980016001750 


\section{References}

1. Weindruch R \& Sohal RS (1997) Caloric intake and aging. $N$ Engl J Med 337, 986-994.

2. Willcox BJ, Yano K, Chen R et al. (2004) How much should we eat? The association between energy intake and mortality in a 36-year follow-up study of JapaneseAmerican men. J Gerontol A Biol Sci Med Sci 59, 789-795.

3. Alberda C, Gramlich L, Jones N et al. (2009) The relationship between nutritional intake and clinical outcomes in critically ill patients: results of an international multicenter observational study. Intensive Care Med 35, 1728-1737.

4. Krishnan JA, Parce PB, Martinez A et al. (2003) Caloric intake in medical ICU patients: consistency of care with guidelines and relationship to clinical outcomes. Chest 124, 297-305.

5. Rubinson L, Diette GB, Song X et al. (2004) Low caloric intake is associated with nosocomial bloodstream infections in patients in the medical intensive care unit. Crit Care Med 32, 350-357.

6. Stapleton RD, Jones N \& Heylan DK (2007) Feeding critically ill patients: what is the optimal amount of energy? Crit Care Med 35, 9 Suppl., S535-S540.

7. Sullivan DH, Sun S \& Walls RC (1999) Protein-energy undernutrition among elderly hospitalized patients: a prospective study. JAMA 281, 2013-2019.

8. Singer P, Anbar R, Cohen J et al. (2011) The tight calorie control study (TICACOS): a prospective, randomized, controlled pilot study of nutritional support in critically ill patients. Intensive Care Med 37, 601-609.

9. Franco M, Ordunez P, Caballero B et al. (2007) Impact of energy intake, physical activity, and population-wide weight loss on cardiovascular disease and diabetes mortality in Cuba, 1980-2005. Am J Epidemiol 166, 1374-1380.

10. Leosdottir M, Nilsson P, Nilsson J-A et al. (2004) The association between total energy intake and early mortality: data from the Malmo Diet and Cancer Study. J Intern Med 256, 499-509.

11. Adams KF, Schatzkin A, Harris TB et al. (2006) Overweight, obesity, and mortality in a large prospective cohort of persons 50 to 71 years old. New Engl J Med 355, 763-778.

12. Harris JA \& Benedict FG (1918) A biometric study of human basal metabolism. Proc Natl Acad Sci U S A 4, 370-373.

13. LaMonte MJ, Blair SN \& Church TS (2005) Physical activity and diabetes prevention. J Appl Physiol 99, 1205-1213.

14. Russell RM (2000) The aging process as a modifier of metabolism. Am J Clin Nutr 72, 2 Suppl., 529S-532S.

15. Buzzard IM \& Feskanich D (1987) Maintaining a food composition data base for multiple research studies: the NCC Food Table. In Food Composition Data: A User's Perspective, pp. 115-122 [WM Rand, editor]. Tokyo: The United Nations University.

16. Nutrition Coordinating Center (1996) Nutrient Database Versions 15-27. Minneapolis, MN: University of Minnesota.
17. Roza AM \& Shizgal HM (1984) The Harris Benedict equation reevaluated. Am J Clin Nutr 40, 168-182.

18. Lee IM, Blair SN, Allison DB et al. (2001) Epidemiologic data on the relationships of calorie intake, energy balance, and weight gain over the life span with longevity and morbidity. J Gerontol A Biol Sci Med Sci 56, 7-19.

19. Doblhammer G, Hoffmann R, Muth E et al. (2006) MicMac bridging the micro-macro gap in population forecasting: the effects of age, sex, education, marital status obesity and smoking on disability and mortality: a systematic literature review. http://www.wiwi.unirostock.de/fileadmin/Institute/ ISD/Lehrstuhl_EmpSozialforschung/Forschungsprojekte/Mic Mac_D18_Trends_in_morbidity_and_mortality.pdf (accessed September 2009).

20. Walter S, Kunst A, Mackenbach J et al. (2009) Mortality and disability: the effect of overweight and obesity. Int J Obes (Lond) 33, 1410-1418.

21. Grabowski DC \& Ellis JE (2001) High body mass index does not predict mortality in older people: analysis of the longitudinal study of aging. I Am Geriatr Soc 49, 968-979.

22. Al Snih S, Ottenbacher KJ, Markides KS et al. (2007) The effect of obesity on disability vs mortality in older Americans. Arch Intern Med 167, 774-780.

23. Diehr P, Bild DE, Harris TB et al. (1998) Body mass index and mortality in nonsmoking older adults: the Cardiovascular Health Study. Am J Public Health 88, 623-629.

24. Alley DE \& Chang VW (2007) The changing relationship of obesity and disability, 1988-2004. JAMA 298, 2020-2027.

25. Diehr P, O'Meara ES, Fitzpatrick A et al. (2008) Weight, mortality, years of healthy life, and active life expectancy in older adults. J Am Geriatr Soc 56, 76-83.

26. Baik I, Ascherio A, Rimm EB et al. (2000) Adiposity and mortality in men. Am J Epidemiol 152, 264-271.

27. Hedlund J, Hansson LO \& Ortqvist A (1995) Short- and longterm prognosis for middle-aged and elderly patients hospitalized with community-acquired pneumonia: impact of nutritional and inflammatory factors. Scand J Infect Dis 27, 32-37.

28. Peake SL, Moran JL, Ghelani DR et al. (2006) The effect of obesity on 12-month survival following admission to intensive care: a prospective study. Crit Care Med 34, 2929-2939.

29. Tremblay A \& Bandi V (2003) Impact of body mass index on outcomes following critical care. Chest 123, 1202-1207.

30. Briefel RR, Sempos CT, McDowell MA et al. (1997) Dietary methods research in the third National Health and Nutrition Examination Survey: underreporting of energy intake. Am J Clin Nutr 65, 4 Suppl., 1203S-1209S.

31. Lee PH, Macfarlane DJ, Lam TH et al. (2011) Validity of the International Physical Activity Questionnaire Short Form (IPAQSF): a systematic review. Int J Behav Nutr Phys Act 8, 115. 